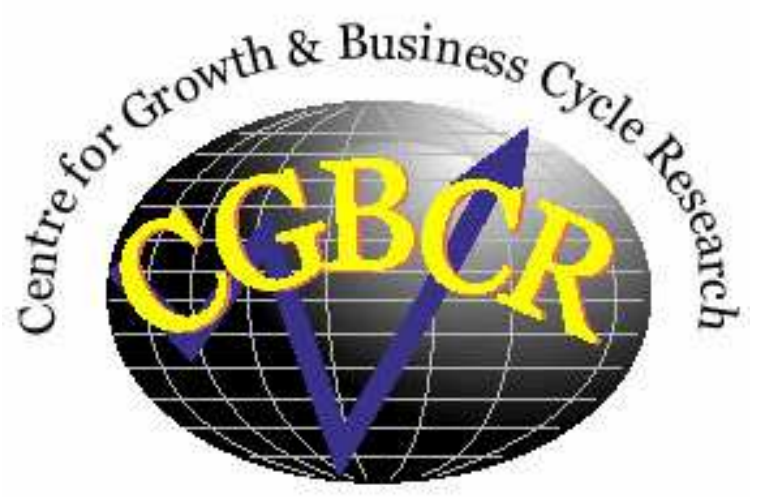

Discussion Paper Series

\title{
Is Volatility Good for Growth? Evidence from the G7
}

By

Elena Andreou ${ }^{*}$, Alessandra Pelloni* and Marianne Sensier ${ }^{\dagger}$

\author{
University of Cyprus \\ *University of Rome, Tor Vergata, Italy
}

${ }^{\dagger}$ Centre for Growth and Business Cycle Research, Economics, School of Social Sciences, University of Manchester, Manchester, M13 9PL, UK

February 2008

Number 097

Download paper from:

http://www.socialsciences.manchester.ac.uk/cgbcr/

discussionpapers/index.html 


\title{
Is Volatility Good for Growth?
}

\author{
Evidence from the G7
}

\author{
Elena Andreou
}

University of Cyprus

Alessandra Pelloni

University of Rome, Tor Vergata

and

\section{Marianne Sensier}

\section{Centre for Growth and Business Cycle Research,}

\section{The University of Manchester}

(email: Marianne.Sensier@manchester.ac.uk)

$6^{\text {th }}$ February 2008

JEL classification: C32, E32, O42.

Keywords: growth uncertainty, learning-by-doing, monetary uncertainty, multivariate GARCH-in-mean, nominal rigidity.

Financial support from the Leverhulme Trust is gratefully acknowledged. The authors would like to thank Louis Christofides, Eric Ghysels, Andros Kourtelos, Denise Osborn, Niki Papadopoulou, Jon Temple and Robert Waldmann for their helpful comments. 


\begin{abstract}
We provide empirical support for a DSGE model with nominal wage stickiness where growth is driven by learning-by-doing and money shocks and their variance are allowed to impact on long-run output growth. In our theoretical model the variance of monetary shocks has a negative effect on growth, while output volatility is good for growth as a positive relationship exists. Utilising a bivariate GARCH-M model we test the empirical conditional mean and variance relationships of nominal money and production growth rates in the G7 countries. We corroborate the theoretical model predictions with evidence from Bonferroni multiple tests across the G7.
\end{abstract}

\title{
I. Introduction
}

This study will investigate the question posed in the title (Is volatility good for growth?) by empirically testing a theoretical growth model with real and nominal shock uncertainty. ${ }^{1}$

Our theoretical analysis is based on a stochastic monetary model of an imperfectly competitive economy with learning-by-doing. Three alternatives are considered with regard to the functioning of the labour market so as to capture the different features in this respect of the countries in our sample: perfect wage flexibility, nominal wage rigidity and wage indexation. In fact while nominal wage

\footnotetext{
${ }^{1}$ Throughout the paper we use the terms uncertainty, volatility and variance interchangeably to define the conditional standard deviation of a variable. For instance, growth uncertainty is equivalent to the volatility/variability of the innovation of output growth rate conditional on its mean dynamic behaviour and that of other variables which is estimated by a parametric dynamic volatility model, the details of which are discussed in the empirical Section III.
} 
rigidities are likely to be present in all the G7 economies, the degree of their presence varies (see Cahuc and Zylberberg 2004, chap.8).

A long-standing tradition in macroeconomics - at both theoretical and empirical levels - is the separation of the study of growth from the study of business cycles. However recently the question of precisely how cyclical fluctuations might affect secular trends has been the subject of an expanding body of literature, analysed by Gaggle and Steindl (2007). In their overview of the theoretical results on volatility and growth Aghion and Banerjee (2005) notice that in "creative destruction" models where production and $R \& D$ are substitutes the relationship between volatility and growth will be positive. However the relationship will become negative if, due to financial markets imperfections, R\&D has to be financed by current profits, a condition more relevant for developing countries.

When growth is driven by learning-by-doing (Romer, 1986), volatility can have a negative effect on growth (see Blackburn, 1999, Pelloni, 1997, Martin and Rogers, 2000 and Blackburn and Galindev 2003). However when taking account of optimal savings de Hek (1999) shows that under learning-by-doing volatility can have a negative effect on growth only if risk aversion is so low to be inconsistent with empirical estimates. Canton (2002) finds a positive relationship in a model where growth is driven by human capital accumulation and Jones et al. (2005) show that the relationship is positive in a large class of convex models of endogenous growth. Coming to monetary models, Dotsey and Sarte (2000) show that in a convex model with perfect price flexibility there will be a positive effect of money volatility on growth, while Blackburn and Pelloni (2004) introduce nominal rigidities in a learningby-doing model and find this effect to be negative. 
The relationship between output uncertainty and growth has also been studied empirically. Some papers find a negative effect based on cross-section (Martin and Rogers, 2000) or panel (Ramey and Ramey, 1995) approaches. Kose, Prasad, and Terrones (2005) provide a comprehensive examination of the cross-sectional relationship over the past four decades and find it to be positive in industrial countries. Evidence from time series work is mixed with positive (Caporale and McKiernan, 1996) and negative (Peel and Speight, 1998) correlations being found. Inflation uncertainty is found to negatively affect output growth in multivariate GARCH models by Elder (2004), Fountas et al. (2006), Grier and Perry (2000) and Grier, et al. (2004). Fountas and Karanasos (2007) find this result does not hold for all the G7 countries in a univariate context.

To preview of our results the theoretical model finds that the variance of nominal shocks is not good for growth as it has a negative effect, while the variance of real shocks is good for growth as it has a positive effect. We test the theoretical hypotheses of our model by empirically investigating linkages between money and output growth and their uncertainties using time-series data spanning four decades for the G7 countries. A bivariate GARCH-in-Mean (GARCH-M) model is estimated that allows growth rates and uncertainties to interact. The money and output growth dynamic equations are a function of their lagged money and output and the timevarying conditional innovation variances that represent the uncertainty factors. We focus on money shocks as they are a direct indicator of monetary policy volatility whereas inflation is contaminated by other shocks within the economy. We find a significant, negative relationship between output growth and nominal money shock uncertainty for some of the G7 countries, in particular those with a higher degree of rigidity in nominal wages, and a significant positive relationship between output 
growth and nominal money growth average for most of the G7. When we apply Bonferonni multiple tests across the G7 countries we find full support for the theoretical predictions of our model.

The structure of the paper is as follows. Section II describes the theoretical model. Section III presents the empirical GARCH-M model and explains the testable hypotheses derived from the theoretical model. Section IV details the empirical results for the G7 countries. Section V concludes the paper.

\section{The Theoretical Analysis}

In this section we present a stochastic monetary model, in which long-run growth is sustained by learning-by-doing. Our setting is similar to the one in Blackburn and Pelloni (2004) however our analysis is somewhat more general as we consider an intermediate sector with imperfect competition and we distinguish three cases as regards the functioning of the labour market (perfect competition, nominal wage setting by unions or wage indexation) and show that results on the effect of money volatility on growth are different in the three cases. In our model an increase in the volatility of preferences leads, through precautionary savings, to an increase in the rate of growth under all assumptions on the labour market. The volatility of money growth will instead reduce the rate of income growth, but only in the case of nominal wage setting. The overall relationship between the rate of growth and its volatility turns out to be positive. We thus show that it is important to isolate the source of volatility, as well as to consider the degree of nominal rigidity in the economy before one can answer the question whether and how volatility affects growth. Another result we derive is that average money growth has a positive effect on average income growth, with nominal 
wage setting, if the variance of money growth does not change. Over the next few sections we will derive our theoretical model.

\subsection{Firms}

There is a continuum of intermediate goods $\mathrm{Y}(i)$ where $i \in(0,1)$. Final output, which can be consumed or invested, is given by

$$
Y_{t}=\left(\int_{0}^{1} Y_{i t}^{\sigma} d i\right)^{1 / \sigma}
$$

where $\sigma \in(0,1)$. Equation (1) displays constant returns to scale. When $\sigma=1$ there is perfect competition in the intermediate sector. The final good sector is competitive.

First order conditions for profit maximization imply demand functions for intermediate goods given by:

$$
P_{i t}=P_{t}\left(\frac{Y_{i t}}{Y_{t}}\right)^{\sigma-1}
$$

where $P_{t}$ is the price of the final good which has a depreciation rate of $100 \%,{ }^{2}$ and $P_{i t}$ is the price of the $i$ th intermediate good.

The technology for producing an intermediate commodity is Cobb-Douglas:

$$
Y_{i t}={\overline{K_{t}}}^{1-\psi} N_{i t}^{\alpha} K_{i t}^{\psi}, \quad \alpha, \psi \in(0,1)
$$

where $N_{i t}$ is labour, $K_{i t}$ capital and $\overline{K_{t}}$ is the economy-wide average capital. 'Learning-by-doing through investing' is a possible rationale for increasing returns to capital, as in Romer (1986), who assumes perfect competition. However, Dasgupta and Stiglitz (1988) notice that learning-by-doing is consistent with perfect competition only at the implausible condition that knowledge is totally non

\footnotetext{
${ }^{2}$ As usual, this hypothesis is needed for obtaining a closed form solution.
} 
excludable. Imperfect competition allows us to consider the case of increasing returns at the firm level, which we obtain when $\alpha+\psi \geq 1$, that is when technical improvements can at least be partially appropriated by the firm (notice the maximand, i.e. profits, is jointly concave in $N_{i t}, K_{i t}$ whenever $\sigma(\alpha+\psi) \leq 1$ so the maximization problem will have a well defined solution). Labour and capital are hired from households at the real wage rate $W_{t} / P_{i t}$ and real rental rate $R_{t}$ respectively, where $W_{t}$ is the nominal wage. By profit maximization we get:

$$
\begin{gathered}
\frac{W_{t}}{P_{i t}}=\alpha \sigma \bar{K}_{t}^{\psi} N_{i t}^{\alpha-1} K_{i t}^{\psi}=\frac{\alpha \sigma Y_{i t}}{N_{i t}}, \\
R_{t}=\phi \bar{K}_{t}^{\psi} N_{i t}^{\alpha} K_{i t}^{\psi-1}=\frac{\psi \sigma Y_{i t}}{K_{i t}} .
\end{gathered}
$$

A free entry condition ensures that profits are zero in equilibrium. To keep things simple we assume every intermediate commodity is produced with the same technology and we focus on a symmetric equilibrium. This means that $Y_{i t}=Y_{t}, K_{i t}=\bar{K}_{t}, N_{i t}=N_{t}, P_{i t}=P_{t}, \forall i$ while:

$$
Y_{t}=N_{t}^{\alpha} K_{t}
$$

and (4) and (5) become:

$$
\begin{gathered}
\frac{W_{t}}{P_{t}}=\alpha \sigma N_{t}^{\alpha-1} K_{t}=\frac{\alpha \sigma Y_{t}}{N_{t}}, \\
R_{t}=\psi \sigma N_{t}^{\alpha}=\frac{\psi \sigma Y_{t}}{K_{t}} .
\end{gathered}
$$

\subsection{Households}


We assume a constant population normalised to one of identical, immortal households. At time $t$, the representative household wants to maximize:

$$
E_{t} U=\sum_{s=0}^{\infty} \beta^{t+s} E_{t}\left[\gamma_{t+s} \log \left(C_{t+s}\right)+\theta \log \left(\frac{M_{t+s-1} \phi_{t+s}}{P_{t+s}}\right)-\lambda L_{t+s}\right], \quad \beta \in(0,1), \theta, \lambda>0
$$

where $E_{t}$ denotes expectations, $C_{t}$ consumption, and $L_{t}$ labour, varying in $[0,1]$ and $\gamma_{t}$ represents a preference shock, at time $t$. The quantity $M_{t-l}$ denotes beginning-of-period $t$ (i.e. end-of-period $t$ - 1 ) nominal cash balances which are increased by a proportional stochastic monetary transfer, $\phi_{t}{ }^{3}$ Money supply, $M_{t}$, is then given by:

$$
M_{t}=M_{t-1} \phi_{t}
$$

We assume that both disturbances $\left\{\gamma_{t}, \phi_{t}\right\}$ are governed by independent, stationary stochastic processes with constant means and constant variances. Moreover the shocks are assumed to have bounded positive supports. The bounds on employment are then always respected (i.e. we do not have corner solutions). The unconditional expected values and variances of the disturbances are denoted, respectively, by $\left\{\mu_{\gamma}, \mu_{\phi}\right\}$ and $\left\{\sigma_{\gamma}^{2}, \sigma_{\phi}^{2}\right\}$. The budget constraint at time $t$ for the household is given by

$$
C_{t}+\frac{M_{t}}{P_{t}}+A_{t+1} \leq \frac{W_{t}}{P_{t}} L_{t}+\frac{M_{t-1} \phi_{t}}{P_{t}}+R_{t} A_{t}+\Pi_{t}
$$

where $A_{t}$ is real assets and $\Pi_{t}$ the firms' profits.

Each agent maximises the expected value of utility subject to its intertemporal budget constraint. Agents are assumed to know the values of all parameters, the current and past values of all variables and the probability distributions of all shocks.

\footnotetext{
${ }^{3}$ The assumption that monetary transfers are proportional (rather than lump-sum) is made for tractability, this is not new (see Benassy 1995).
} 
Households choose consumption, money balances and asset holdings according to the following necessary conditions:

$$
\begin{gathered}
\frac{\gamma_{t}}{C_{t}}=\beta E_{t}\left(\frac{\gamma_{t+1} R_{t+1}}{C_{t+1}}\right), \\
\frac{\gamma_{t}}{P_{t} C_{t}}=\frac{\theta}{M_{t}}+\beta E_{t}\left(\frac{\gamma_{t+1} \phi_{t+1}}{P_{t+1} C_{t+1}}\right),
\end{gathered}
$$

We now spell out our three alternative assumptions on the labour market. Coming to the labour market: the first is perfect competition between workers with wage flexibility, the second is nominal wage setting by unions and the third is real wage setting by unions. Under the first assumption, perfect competition between workers with wage flexibility, a further optimising condition is:

$$
\lambda P_{t} C_{t}=\gamma_{t} W_{t}
$$

which simply equates the wage to the marginal rate of substitution between consumption and leisure. Under the second assumption monopolistic unions choose a nominal wage at which households supply whatever labour is demanded by firms. We assume that wage setting takes place prior to the realisation of shocks on the basis of one-period contracts and that the contract wage is chosen so as to maximise households' expected utility, taking into account labour demand. The optimal wage is then found to satisfy

$$
\lambda E_{t-1}\left(N_{t}\right)=\alpha W_{t} E_{t-1}\left(\frac{\gamma_{t} N_{t}}{P_{t} C_{t}}\right)
$$

Finally under the third assumption monopolistic unions choose a real wage $w_{t}^{*}$ for the following period and households supply whatever labour is demanded by firms at that wage. The nominal wage $W_{t}$ is given by: $W_{t}=w_{t}^{*} P_{t}$ In words the nominal wage is indexed to the price level so as to reach the level of the real wage set in the previous 
period. At time $t-1$ the real wage which maximises the expected utility of workers, given labour demand, is:

$$
\frac{\lambda}{E_{t-1}\left(\alpha \gamma_{t} / C_{t}\right)}=w_{t}^{*}
$$

The equilibrium behaviour of the household is characterised completely by the firstorder conditions in (8) and (9), the budget constraint (10), either (13) or (13') or (13'), and finally the transversality conditions

$$
\lim _{{ }_{\tau \rightarrow \infty}} \beta^{\tau} E_{t}\left(\left(\gamma_{t+\tau} M_{t+\tau-1} \phi_{t+\tau}\right) / P_{t+\tau} C_{t+\tau}\right)=\lim _{\cdot \tau \rightarrow \infty} \beta^{\tau} E_{t}\left(\gamma_{t+\tau} A_{t+\tau+1} / C_{t+\tau}\right)=0 .
$$

\subsection{General Equilibrium}

The general equilibrium solution is computed by combining the optimising conditions obtained so far with the market clearing conditions $C_{t}+K_{t+1}=Y_{t}$ (for goods), $\quad K_{t}=A_{t}$ (for capital), and $N_{t}=L_{t}$ (for labour) plus the already assumed one that money supply equals money demand. The following relations are then obtained (see Appendix A for details):

$$
\begin{gathered}
C_{t}=\frac{(1-a) \gamma_{t}}{(1-a) \gamma_{t}+a \mu_{\gamma}} Y_{t}, \\
\frac{M_{t}}{P_{t}}=\frac{(1-a) \theta}{(1-\beta)\left[(1-a) \gamma_{t}+a \mu_{\gamma}\right]} Y_{t}, \\
K_{t+1}=\frac{a \mu_{\gamma}}{(1-a) \gamma_{t}+a \mu_{\gamma}} Y_{t},
\end{gathered}
$$

where $a \equiv \sigma \beta \psi$. For a given level of output, consumption increases while investment and money demand decrease with higher realisations of the demand shock, $\gamma_{t}$. These responses are non-linear: an increase in the volatility of preference shocks causes a rise in the average shares of investment and money demand. Also notice that these shares 
are not influenced by money shocks or the structure of the labour market. Finally notice that the rate of saving is increasing in $\sigma$.

If the labour market is competitive we have:

$$
N_{t}=\frac{\sigma \alpha\left[(1-a) \gamma_{t}+a \mu_{\gamma}\right]}{\lambda(1-a)}
$$

with nominal wage contracts:

$$
N_{t}=\frac{\alpha^{2} \sigma\left[(1-a) \gamma_{t}+a \mu_{\gamma}\right] \phi_{t}}{\lambda(1-a) \mu_{\phi}}
$$

and with wage indexation:

$$
N_{t}=\frac{\alpha^{2} \sigma \mu_{\gamma}}{\lambda(1-a)}
$$

(derivations can be found in the Appendix A). In all cases the higher is the elasticity of substitution between intermediates and the higher is the average of the demand shock the higher is employment. In the first case and in the third case, money is neutral. If the labour market is competitive employment responds linearly to the current preference shock so its expected value does not depend on the variance of the shock. Under total wage indexation labour does not respond to shocks (it would if more shocks were considered, for instance technology shocks). Finally in the case of nominal wage setting employment is linear in both shocks.

\subsection{Growth and Cycles}

If the labour market is competitive, using (6), (16) and (17) we get:

$$
\Delta Y_{t}:=\frac{Y_{t+1}}{Y_{t}}=\frac{a \mu_{\gamma}}{(1-a) \gamma_{t}+a \mu_{\gamma}}\left[\frac{\sigma \alpha\left[(1-a) \gamma_{t+1}+a \mu_{\gamma}\right]}{\lambda(1-a)}\right]^{\alpha}
$$

The rate of growth is concave in the current realisation of the preference shock, due to the decreasing marginal productivity of labour. The rate of growth is however convex 
in the lagged realisation of the shock. This is because of saving behaviour: from (16) we see that the propensity to save out of current income is a convex function of the preference shock. This is transmitted linearly to production, given the constant marginal productivity of capital. We have, using a second order approximation:

$$
\begin{gathered}
E(\Delta Y):=E\left(\frac{Y_{t+1}}{Y_{t}}\right) \cong A\left(1+\frac{(1-a)^{2}[\alpha(\alpha-1)+2]}{2 \mu_{\gamma}^{2}} \sigma_{\gamma}^{2}\right) \\
\operatorname{var}(\Delta Y):=\operatorname{Var}\left(\frac{Y_{t+1}}{Y_{t}}\right) \cong \frac{A^{2}(1-a)^{2}\left(\alpha^{2}+1\right)}{\mu_{\gamma}{ }^{2}} \sigma_{\gamma}^{2}
\end{gathered}
$$

where $\mathrm{A}=a\left(\frac{\sigma \alpha \mu_{\gamma}}{\lambda(1-a)}\right)^{\alpha}$. The lower is the market power of firms (the higher is $\sigma$ ) the higher are both the mean and the variance of growth. Both moments are also increasing in the variance of the preference shock: the positive effect of this variance on the rate of growth through the precautionary saving channel more than offsets the negative effect through the employment channel.

Let us now consider the economy with nominal contracts. We have, using (6), (16) and (17')

$$
\Delta Y_{t}:=\frac{Y_{t+1}}{Y_{t}}=\frac{a \mu_{\gamma}}{(1-a) \gamma_{t}+a \mu_{\gamma}}\left[\frac{\sigma \alpha^{2}\left[(1-a) \gamma_{t+1}+a \mu_{\gamma}\right] \phi_{t+1}}{\lambda(1-a) \mu_{\phi}}\right]^{\alpha}
$$

The growth rate of output, $\Delta Y_{t}$, is now dependent on the realisations of both real and nominal shocks. The mean and variance of the growth rate are approximated, respectively, by

$$
\begin{gathered}
E(\Delta Y):=E\left(\frac{Y_{t+1}}{Y_{t}}\right) \cong \alpha^{\alpha} A\left(1+\frac{(1-a)^{2}[\alpha(\alpha-1)+2]}{2 \mu_{\gamma}^{2}} \sigma_{\gamma}^{2}+\frac{\alpha(\alpha-1)}{2 \mu_{\phi}^{2}} \sigma_{\phi}^{2}\right) \\
\operatorname{var}(\Delta Y):=\operatorname{Var}\left(\frac{Y_{t+1}}{Y_{t}}\right) \cong\left(\alpha^{\alpha} A\right)^{2}\left(\frac{(1-a)^{2}\left(\alpha^{2}+1\right)}{\mu_{\gamma}^{2}} \sigma_{\gamma}^{2}+\frac{\alpha^{2}}{\mu_{\phi}^{2}} \sigma_{\phi}^{2}\right)
\end{gathered}
$$


By comparing (19) and (19') we see that the impact on average growth of the variance of real shocks is strictly analogous with or without contracts, so the previous analysis holds. As for money shocks, we can notice that with zero variance in money growth there are no effects of average money growth on output growth. Money super-neutrality under certainty is in fact expected when, as in our model, the utility function is additively separable in consumption, money and labour (see Wang and Yip, 1992). For a given variance of money growth, an increase in average money growth leads to higher output growth because it means an improvement in the information available to agents when they choose the nominal wage and a reduction in the related distortion. In general average growth falls while its cyclical volatility rises with an increase in the variance of the monetary growth shock. This type of disturbance impacts on growth through its (linear) effect on employment, of which output is a concave function, by virtue of diminishing returns to labour. The fact that the average and the variance of money growth have opposite effects on output growth, together with the fact that in reality the two tend to be highly correlated, may provide a partial rationale for some of the inconclusive results in the empirical literature of growth and inflation.

Finally for the economy with wage indexation we have:

$$
\Delta Y_{t}:=\frac{Y_{t+1}}{Y_{t}}=\frac{\alpha^{\alpha} A \mu_{\gamma}}{(1-a) \gamma_{t}+a \mu_{\gamma}} .
$$

and approximating:

$$
\begin{gathered}
E(\Delta Y):=E\left(\frac{Y_{t+1}}{Y_{t}}\right) \cong \alpha^{\alpha} A\left[1+(1-a)^{2} \sigma_{\gamma}^{2} / \mu_{\gamma}^{2}\right] \\
\operatorname{Var}\left(\frac{Y_{t+1}}{Y_{t}}\right) \cong \alpha^{2 \alpha} A^{2}(1-a)^{2} \frac{\sigma_{\gamma}^{2}}{\mu_{\gamma}^{2}}
\end{gathered}
$$


As in the case of a perfectly competitive labour market, money has no real effects, while the variance of the demand shock has a positive effect on growth. This effect, for plausible values of $\alpha$, will be lower than in the competitive case.

For the purposes of the empirical analysis we combine equations (19) and (20) (or (19') and (20') or (19') and (20'))) to derive a relationship between output growth and its variance. We obtain (21), (21') and (21'’), the first pertaining to an economy with a perfectly competitive labour market, the second to an economy with nominal contracts and the third to an economy with wage indexation:

$$
\begin{gathered}
E(\Delta Y) \cong A+\frac{[\alpha(\alpha-1)+2]}{2 A\left(\alpha^{2}+1\right)} \operatorname{var}(\Delta Y) \\
E(\Delta Y) \cong \alpha^{\alpha} A+\frac{[\alpha(\alpha-1)+2]}{2 \alpha^{\alpha} A\left(\alpha^{2}+1\right)} \operatorname{var}(\Delta Y)-A \frac{\alpha^{\alpha+1}(\alpha+1)}{\left(\alpha^{2}+1\right)} \frac{\sigma_{\phi}^{2}}{2 \mu_{\phi}^{2}} \\
E(\Delta Y) \cong \alpha^{\alpha} A+\frac{\operatorname{var}(\Delta Y)}{A \alpha^{\alpha}}
\end{gathered}
$$

It is now evident that the mean and the variance of output growth will be positively correlated, both with a competitive labour market, with nominal wage setting and with total wage indexation whereas monetary shock uncertainty will have a negative effect (or no effect) on average output depending on the structure of the labour market. Moreover, under nominal wage setting the average money growth will have a positive effect on average output growth. These theoretical propositions constitute empirically testable hypotheses as demonstrated in the context of the empirical models below.

\section{GARCH-M Model}

In this section we present the details of the empirical model and its connection with the theoretical model, the results follow in Section IV. 
The multivariate Generalised AutoRegressive Conditional Heteroscedastic in Mean (GARCH-M) model provides the setup for examining a set of hypotheses that evaluate if there is empirical support for the above theoretical propositions. The relationship between money and output and their uncertainties is modelled by a bivariate GARCH-M $(1,1)$ with constant conditional correlation in the spirit of Bollerslev (1990):

$$
\begin{gathered}
\Delta M_{t}=\beta_{0}+\sum_{i=1}^{p} \beta_{1 i} \Delta M_{t-i}+\sum_{i=1}^{q} \beta_{2 i} \Delta Y_{t-i}+\beta_{3} \sigma_{\Delta M, t}^{2}+\beta_{4} \sigma_{\Delta Y, t}^{2}+\varepsilon_{t} \\
\sigma_{\Delta M, t}^{2}=\alpha_{0}+\alpha_{1} \varepsilon_{t-1}^{2}+\alpha_{2} \sigma_{\Delta M, t-1}^{2} \\
\Delta Y_{t}=\beta_{5}+\sum_{i=1}^{p} \beta_{6 i} \Delta Y_{t-i}+\sum_{i=1}^{q} \beta_{7 i} \Delta M_{t-i}+\beta_{8} \sigma_{\Delta M, t}^{2}+\beta_{9} \sigma_{\Delta Y, t}^{2}+v_{t} \\
\sigma_{\Delta Y, t}^{2}=\alpha_{3}+\alpha_{4} v_{t-1}^{2}+\alpha_{5} \sigma_{\Delta Y, t-1}^{2} \\
\operatorname{COV}=\rho_{t} \sigma_{\Delta M, t} \sigma_{\Delta Y, t}
\end{gathered}
$$

Equation (22) describes the dynamic conditional mean of nominal money growth, $\Delta M_{t}$, as a function of the past history of both money and real output growth, $\Delta Y_{t}$, and their conditional variances given by $\sigma_{\Delta M, t}^{2}$ and $\sigma_{\Delta Y, t}^{2}$, respectively, which are estimated by equations (23) and (25). Equation (23) is the conditional variance of nominal money growth shocks and represents a parametric measure of money uncertainty that affects the conditional mean equations of money growth (22) as well as output growth (24). Equation (23) captures the time-varying behaviour of uncertainty as shown by the autoregressive structure of $\sigma_{\Delta M, t}^{2}$ which may be associated with time-varying policy shocks. In an analogous manner equation (25) is the conditional variance of innovations in output growth. Equation (24) describes the conditional mean of real output growth as a function of lags of output and money growth and their conditional variances and represents the empirical counterpart of 
equations (21), (21') and (21')). Finally (26) specifies the constant conditional covariance between $\varepsilon_{t}$ and $v_{t}$. It is assumed that the two error terms, $\varepsilon_{t}$ and $v_{t}$, are jointly conditionally normal with zero means and conditional variance given by equations (23) and (25). ${ }^{4}$ The above system of equations allows for the feedback relationship between the two variables and models jointly both the conditional mean and variance (or linear and nonlinear) dynamics which are estimated simultaneously using Maximum Likelihood methods. In the context of equation (24) we examine the empirical support of the theoretical propositions regarding the effects of nominal money and output growth uncertainty, $\sigma_{\Delta M, t}^{2}$ and $\sigma_{\Delta Y, t}^{2}$ respectively, on growth $\Delta Y_{t}$. In order to explain the difference in the notation between the empirical and theoretical models we note that in the former specification the time series processes of money and output growth, denoted by $\Delta M_{t}$ and $\Delta Y_{t}$ respectively, are governed by dynamics in the conditional mean and variances, $E_{t-1}\left(\Delta M_{t}\right), E_{t-1}\left(\Delta Y_{t}\right)$ and $\sigma_{\Delta M, t}^{2}, \sigma_{\Delta Y, t}^{2}$, respectively, and specified by the bivariate GARCH-M equations above. In order to explain the difference in the notation between the empirical and theoretical models we note that in the former specification the time series processes of money and output growth, denoted by $\Delta M_{t}$ and $\Delta Y_{t}$ respectively, are governed by dynamics in the conditional mean and variances, $E_{t-1}\left(\Delta M_{t}\right), E_{t-1}\left(\Delta Y_{t}\right)$ and $\sigma_{\Delta M, t}^{2}, \sigma_{\Delta Y, t}^{2}$, respectively, and specified by the bivariate GARCH-M equations above. In the theoretical model (equations (21), (21'), (21'’)) $E(\Delta Y)\left(\mu_{\phi}\right)$ indicates both the conditional and the unconditional mean of output (money) growth due to the simplifying assumptions needed for tractability, which imply that the process for output (money) growth is not

\footnotetext{
${ }^{4}$ Inflation is endogenous in our model. Hence we focus on money and output growth that closely match the theoretical model predictions.
} 
autoregressive, but only depends on parameters and innovations. The same is true for the uncertainties of output and money growth, $\operatorname{var}(\Delta Y)$ and $\sigma_{\phi}^{2}$ which in the theoretical model are assumed to be constant over time, again for tractability.

The GARCH-M model is also adopted in Elder (2004) and Grier and Perry (2000) to study the relationship between US growth, inflation and their volatilities, as well as Fountas et al. (2006) and Fountas and Karanasos (2007) for the G7. The parametric measure of volatility implied by the GARCH specifications captures a measure consistent with our theoretical notion of uncertainty as the variance of the unpredictable innovation of a variable (e.g. Cukierman and Meltzer, 1986), instead of simply calculating the unconditional standard deviations of money and output growth. ${ }^{5}$

The stationarity and dependence properties of the volatility equations (23) and (25) provide a framework to interpret the effects of shocks in the uncertainty of output and nominal money growth rates. ${ }^{6}$ The model allows us to examine three different useful aspects of volatilities: (i) if output growth uncertainty follows a GARCH process then we can evaluate if the variance of output growth or other economic variables have a significant temporal component; (ii) if the GARCH output dynamic coefficients, e.g.

\footnotetext{
${ }^{5}$ Note that although we have a measure of conditional innovation uncertainty we do not consider the Levine and Renelt (1992) conditioning information set as Ramey and Ramey (1995) since we follow a time-series approach and some of those variables are either not available at the monthly frequency or do not exhibit any temporal variation for studying in a time series context. Although additional explanatory variables can augment our conditional mean equations at this stage we choose to focus an empirical model as close as possible to our theoretical model by considering a bivariate model of five simultaneous equations for each country and joint hypotheses tests for all the G7 countries.

${ }^{6}$ The variables are assumed to be stationary, a hypothesis that is empirically examined prior the estimation of the model using unit root tests which leads us to consider the first differences of the above series.
} 
$\left(\alpha_{1}+\alpha_{2}\right)$ in equation (23), are statistically significant and close to unity then it implies an Integrated GARCH process (IGARCH) according to which shocks in output uncertainty are expected to have a significant and persistent effect on the variance of money growth; and (iii) if in addition the relationship between the mean and volatility is empirically supported by a GARCH-in-Mean process then it implies a significant effect of uncertainty on the average of output growth. This is due to the fact that the variance enters the conditional mean growth equation and its partial correlation with output can be examined in the presence of other uncertainty factors as well as other mean/average growth rate factors. Hence this model provides a context to disentangle the mean and variance effects of say nominal money on output growth by modelling all the conditional moments and estimating their interactions simultaneously. In addition, it allows us to examine the causality-in-mean and in-variance hypotheses (Granger, 1988) which relate to our theoretical propositions regarding the direction of causality of the uncertainty of real and nominal shocks on growth. Last but not least, the GARCH-M model allows us to disentangle the empirical effects of the average and the variance of money growth on output growth by jointly estimating a system of dynamic conditional moments. Indeed, some studies emphasize that it is difficult to separate the effects of inflation/money average and variance on growth given the high correlation between the two variables (Temple, 2000, Dotsey and Sarte, 2000).

We now turn to the testable hypotheses relating to the theoretical predictions of the model analysed in Section II regarding the effects and sources of uncertainty on growth for the G7 countries using the GARCH-M model. Money growth, $\Delta M_{t}$, is measured by the rate of growth of the narrow nominal money supply and output growth, $\Delta Y_{t}$, by the index of production (IOP) growth rates. 
The model is estimated using monthly, seasonally adjusted data for the G7 countries over the maximum sample 1960 to $2006 .^{7}$ The choice of monthly sampling frequency reflects the objective to estimate conditional variances from short-run cyclical dynamics and time-varying policy shocks. The monthly difference of production with lags of up to a year is an attempt to capture both short- and relatively long-run growth effects. The G7 represents the group of homogenous countries that more closely correspond to the theoretical assumptions of the model. The details of the data including sources and outliers removed are summarised in Appendix B.

We estimate the empirical model in equations (22)-(26) for each country and our objective is to examine the support of the following theoretical model propositions using hypothesis tests for both the individual, country-specific and multiple, G7-group.

- Hypothesis (i) examines whether nominal money uncertainty is time varying as modelled by the GARCH equation (23) (where $\mathrm{H}_{0}: \alpha_{1}=\alpha_{2}=0$ ). If the sum of these GARCH coefficients is close to unity then a shock in money uncertainty will have a persistent effect.

- Hypothesis (ii) tests whether the growth uncertainty specified in equation (25) provides a time varying measure of the growth variability $\left(\mathrm{H}_{0}: \alpha_{4}=\alpha_{5}=0\right)$.

- Hypotheses (iii) $\left(\mathrm{H}_{0}: \beta_{3}=0\right)$ and (iv) $\left(\mathrm{H}_{0}: \beta_{4}=0\right)$ examine the significance of money and output uncertainty, respectively, in the money equation (22).

- Hypotheses (v) $\left(\mathrm{H}_{0}: \beta_{8}=0\right)$ and (vi) $\left(\mathrm{H}_{0}: \beta_{9}=0\right)$ examine the effects of money and growth uncertainty, respectively, in the output equation (24). The alternative hypotheses, $\mathrm{H}_{1}: \beta_{8}<0$ and $\mathrm{H}_{1}: \beta_{9}>0$ derive their signs from the

\footnotetext{
${ }^{7}$ This sample period refers to Canada, France, Japan and the US. Due to data availability the sample for Italy is 1965-2006, for Germany, 1960-2003 and for the UK the 1970-2006.
} 
theoretical predictions (see equations (21), (21') and (21'’)). Note that the first coefficient is predicted to be negative if there is nominal rigidity.

- Hypothesis (vii) $\left(\mathrm{H}_{0}: \beta_{7 i}=0, i=1, \ldots, q\right)$ examines the effects of money growth on output growth in equation (24). The alternative hypothesis derived from the theoretical model suggests that the overall effect will be positive, after controlling for its variance effects and if there are nominal wage contracts (see equation (21')).

\section{Empirical Results}

In this section we discuss the empirical support of the hypotheses detailed in the previous section using the bivariate GARCH-M models for the G7 countries. Table 1 presents the summary results for each hypothesis tested and the corresponding estimated GARCH-M coefficients and t-statistics. The detailed estimation and misspecification results of equations (22)-(26) for each country can be found in Appendix C. ${ }^{8}$ The estimation utilises the BFGS numerical optimisation algorithm with robust standard errors to calculate the maximum likelihood estimates of the parameters in (22)-(26) (estimated in RATS 6.3 using the GARCH wizard). The general-to-specific procedure is adopted for specifying the significant lags in the linear equations.

First we investigate the significance of the conditional volatility estimates for money and growth since they represent the building blocks of the theoretical and empirical models. The results of hypotheses (i) and (ii) in Table 1 provide strong evidence regarding the significance of the GARCH parameters $\alpha_{i}$ 's governing the estimated conditional variances in all countries (except the output volatility for Japan).

\footnotetext{
${ }^{8}$ Appendix $\mathrm{C}$ is available from the authors on request or to download from the web-site http://www.socialsciences.manchester.ac.uk/disciplines/economics/research/discussionpapers/.
} 
These results unfold an interesting property of these macroeconomic variables for the G7, namely the existence of nonlinear dynamics present in their conditional variances. In addition, we provide evidence regarding the effects of shocks in the nominal uncertainty as measured by the volatility persistence of money. In the GARCH equation (23) of money growth the persistence coefficient, $\left(\alpha_{1}+\alpha_{2}\right)$, is close to unity for Canada, France, Japan and the US, which implies that shocks in nominal money uncertainty have a persistent effect in these countries. ${ }^{9}$ Similarly, the countries characterised by significant and persistent volatility dynamics in output growth, $\left(\alpha_{4}+\alpha_{5}\right)$ in equation (25), are Italy and the UK.

Next we examine the effects of nominal money shock variability, $\sigma_{\Delta M, t}^{2}$, and growth uncertainty, $\sigma_{\Delta Y, t}^{2}$, on money growth (shown in equation (22) and tested via hypotheses (iii) and (iv)) and on output growth (shown in equation (24) and examined by hypotheses (v) and (vi)). As mentioned earlier, the latter is particularly interesting given the theoretical proposition that nominal shock uncertainty exerts a negative effect on growth if there are nominal rigidities. We investigate this hypothesis using two statistical procedures. First, we test each individual hypothesis for each country separately at a given level of significance, $\alpha$. Second, we combine these $k=1, . ., 7$ individual hypotheses and apply a multiple test of significance based on a Bonferroni procedure. In this context we view each of the $\mathrm{G} 7$ as an alternative sample realisation that yields individual statistics used to examine the empirical support for the global G7 null hypothesis made up of the intersection of the individual null hypotheses such that

\footnotetext{
9 Diebold (1986) and Lamourex and Lastrapes (1990) present empirical evidence that volatility persistence may be a spurious effect due to structural breaks or outliers in the sample. However, in the present analysis the estimated persistence effects are not due to outliers since these have been removed from the data before the estimation as shown in Table B2.
} 
$\mathrm{H}_{0}{ }^{\mathrm{g}}=\left\{\mathrm{H}_{0}{ }^{\mathrm{k}}, \mathrm{k}=1, \ldots, 7\right\}$. Appropriate methods are adopted to adjust the significance level to the multiple hypothesis test and a sequential test is performed to examine the sources of rejection, discussed below. If no empirical support is found for any of the $\mathrm{H}_{0}{ }^{\mathrm{k}}$ at the adjusted significance level then we conclude that there is no empirical support for the global null hypothesis for the G7 group. ${ }^{10}$

Following the individual hypothesis test approach we find that nominal shock uncertainty has a negative effect on monetary growth in all the G7 and a significant one in Canada, Italy (at the 5\% significance level) and Japan (at the 10\% significance level) as shown in Table 1 for hypothesis (iii). In addition, output uncertainty has a significant positive effect on money growth in Italy and the UK (shown in Table 1, hypothesis (iv)). More interestingly, turning to the output growth equation (24), we examine the empirical support of the theoretical prediction that nominal uncertainty has a negative effect on output growth. Table 1 (hypothesis (v)) shows that money uncertainty has a negative effect on output growth in four of the G7 and reports that this is significant in two of the G7 countries, namely Canada and Germany. The exceptions to this result are France, Italy and the UK where the estimated money uncertainty variable is positive although insignificant. This can be interpreted using our theoretical analysis by recalling that nominal volatility will have negative effects on growth only if there is nominal wage rigidity, which is estimated to be higher in the US and Canada (see Cahuc and Zylberberg 2004 chap 8). France, Italy and the UK had at times a very high degree of wage indexation and underwent periods of high inflation, see Bruno and Sachs (1986) and Manacorda (2002). In particular the UK had a period of high inflation in the seventies: Card and Hyslop (1997) among many others provide evidence that in a

\footnotetext{
${ }^{10}$ The Bonferroni procedure is valid even if the alternative individual statistics of the hypotheses $\mathrm{H}_{0}{ }^{\mathrm{k}}$ are not strictly independent (see for instance, Gourieroux and Monfort, 1996).
} 
higher inflation environment wage adjustments occur more quickly thus reducing the degree of nominal wage stickiness. In the other economies price indexation has always been very limited (the US) or forbidden by law (Germany). In addition we examine hypothesis (vi) regarding the effects of output uncertainty on growth. In Table 1 output uncertainty turns out to be positive for six of the G7 and it is significant in Canada, France and the US. This is consistent with our theoretical predictions and distinguishes our work from many other studies that find a negative effect of volatility on growth.

The last hypothesis (vii) refers to the effect of money growth on output growth. The joint F-test for zero restrictions on the lagged coefficients of $\Delta M_{t-i}, \beta_{7 i}$, provides strong evidence against the null hypothesis for all countries except Italy and the UK. The reported sum of $\beta_{7 \mathrm{i}}$ coefficients supports our theoretical model prediction that nominal money growth has a positive effect on output growth (apart from the UK). To explain these results we recall that this prediction is conditional on the degree of nominal rigidity, which is likely to be very low in Italy and the UK during some periods, as mentioned above.

We now turn to the Bonferroni multiple test procedure for the global G7 hypothesis $\mathrm{H}_{0}{ }^{\mathrm{g}}$ which has an asymptotic bound with significance levels of $\alpha^{\mathrm{k}}=0.007$ and 0.014 (given $\alpha=5 \%$ and 10\%, respectively). Hochberg (1988) and Rom (1990) inter alia, suggest a modified Bonferroni approach following a sequentially rejective procedure according to which one starts by examining the largest $p$-value, $p(m)$, of the individual hypotheses, $\mathrm{H}_{0}{ }^{\mathrm{k}}$. If $p(m) \leq \alpha^{\mathrm{k}}$ then all hypotheses are rejected. If not, then one cannot reject $\mathrm{H}_{0}{ }^{\mathrm{g}}$ and goes on to compare the next largest $p$-value, $p(m-1)$, with an adjusted confidence interval based on the reduction of the sample size. If that is not rejected the above procedure is implemented in a sequential manner. Following the multiple significance test approach the empirical results show that the global null 
hypothesis for (iv) is rejected for the G7 group. This implies that output uncertainty has a significant effect on monetary growth given that the maximum $t$-value for hypothesis (iv) is $t(m)=3.73$ which yields an equivalent Bonferroni adjusted $p$-value, $p(m)=0.0001$. In addition, the global hypothesis (iii) is rejected by the data (at the $10 \%$ significance level) since the Bonferroni procedure yields $t(m)=2.40$ and corresponding $p(m)=0.0082$. Hence money uncertainty has a significant, negative effect on money growth at the $10 \%$ multiple test significance level. Yet, more importantly, the multiple test results for hypotheses (v) and (vi) show that both money and output volatilities have a significant effect on output growth. Specifically, the Bonferroni adjustment shows that money volatility in the G7 yields a significant, negative effect on output based on $t(m)=2.33$ and $p(m)=0.0099$ (at the $10 \%$ Bonferroni significance level). Similarly, output uncertainty has a significant positive effect on output growth since $t(m)=2.78$ and $p(m)=0.0027$.

Furthermore, we have performed some robustness checks for the above empirical findings. We have examined the sensitivity of the above results using other measures of money aggregates. We find that similar results apply especially with respect to nominal money shock uncertainty. Moreover, for some of the G7 we expand the information set to include some additional explanatory variables in the conditional mean equations such as short-run interest rates and find that the above results still hold. In addition, we find similar qualitative results to other parametric volatility models which incorporate asymmetries such as the Exponential GARCH (EGARCH) specifications. Finally, we find that the correlation coefficient in equation (26) is significant for Canada, France and Japan and time-invariant for all the countries. 


\section{Conclusions.}

The paper contributes to the analysis of the relationship between growth and its volatility by examining how the short-run nominal money uncertainty affects output growth. The theoretical model predicts that the variability of output shocks yields a positive effect on growth while variability of nominal shocks has a negative effect on growth, in economies with nominal wage rigidity. Moreover, in these economies the average money growth has a positive effect on growth and after controlling for the money uncertainty effect. In the context of a bivariate GARCH-M model, we empirically investigate the effects of nominal money shock and output growth uncertainties on output growth by estimating simultaneously the effects of the dynamic volatilities of monthly money and output growth for the G7 countries in the conditional mean equations of the money and output growth rates.

Summarising the empirical analysis we derive the following results. First, there is strong evidence of significant conditional heteroskedasticity effects in the time series behaviour of monthly production and nominal money growth rates during the period of the early 1960 s to 2006 . Shocks to nominal money growth uncertainty have a persistent effect in Canada, France, Japan and the US whereas shocks to output uncertainty are relatively less persistent in the G7 except in Italy and the UK. Second, there is a positive and significant effect of output growth uncertainty on growth in the G7 using the Bonferroni procedure. Following the individual hypothesis we find empirical support for this hypothesis for Canada, France and the US. Third, there is some evidence of a negative and significant effect of nominal money shock uncertainty on output growth in the G7 using the Bonferroni inequality for a multiple hypothesis test (with $10 \%$ significance level). Following the individual hypothesis test approach we find that nominal money shocks uncertainty exerts a significant influence on growth in 
Canada and Germany. A possible explanation of the insignificant and non-negative effects of nominal money uncertainty in the growth equation in France, Italy, Japan and the UK could be the wage indexation and the high inflation experienced in the 1970s by these economies. Finally, the empirical analysis also presents evidence that average money growth has a positive effect on the average output growth for the majority of the G7.

This paper shows that it can be instructive to use an approach that separates nominal and growth uncertainties to understand how these relate to long-run growth both theoretically and empirically. Overall our answer to our question is YES - output volatility is good for growth for all the G7 using the multiple test approach.

\section{References}

Aghion P. and A. Banerjee, (2005). Volatility and Growth. Oxford University Press: Oxford, UK.

Benassy, J.P. (1995). 'Money and wage contracts in an optimising model of the business cycle.' Journal of Monetary Economics, 35, 303-15.

Blackburn, K. (1999). 'Can stabilisation policy reduce long-run growth?' Economic Journal, 109, 67-77.

Blackburn, K. and Galindev, R. (2003). 'Growth, volatility and learning.' Economics Letters, 79(3), 417-421.

Blackburn, K. and Pelloni, A. (2004). 'On the relationship between growth and volatility.' Economics Letters, 83, 123-128.

Bollerslev, T. (1990). 'Modeling the coherence in short-run nominal exchange-rates - a multivariate generalized ARCH model.' Review of Economic Statistics, 72, 498-505.

Bruno, M. and Sachs, J. (1985). Economics of Worldwide Stagflation, Basil Blackwell: Oxford, UK.

Canton, E. (2002). 'Business cycles in a two-sector model of endogenous growth.' Economic Theory, 19, 477-492.

Cahuc, P. and Zylberberg, A. (2004) Labour Economics, MIT Press: Cambridge, Massachusetts - London, England.

Caporale, T. and McKiernan, B. (1996). 'The relationship between output variability and growth: evidence from post-war UK data.' Scottish Journal of Political Economy, 43, 229-236. 
Card, D. and Hyslop, D. (1997). Does Inflation "Grease the Wheels of the Labor Market"? in Reducing Inflation: Motivation and Strategy. C. Romer and D. Romer, eds., University of Chicago Press: Chicago.

Cukierman, A. and Meltzer, A. (1986). 'A theory of ambiguity, credibility, and inflation under discretion and asymmetric information.' Econometrica, 54, 1099-1128.

Dasgupta, P. and Stiglitz, J. (1988). 'Learning-by-doing, market structure and industrial and trade policies.' Oxford Economic Papers, 40, 246-268.

de Hek, P.A. (1999). 'On endogenous growth under uncertainty.' International Economic Review, 40, 727-744.

Diebold, F.X. (1986). 'Modelling the persistence of conditional variances: A comment.' Econometric Reviews, 5, 51-56.

Dotsey, M. and Sarte, P.D. (2000). 'Inflation uncertainty and growth in a cash-inadvance economy', Journal of Monetary Economics 45, 631-655.

Elder, J. (2004). 'Another perspective on the effects of inflation uncertainty.' Journal of Money, Credit and Banking, 36 (5), 911-928.

Fountas S., Karanasos, M. and Kim, J. (2006). 'Inflation uncertainty, output growth uncertainty and macroeconomic performance.' Oxford Bulletin of Economics and Statistics, 68(3), 319-343.

Fountas S. and Karanasos, M. (2007). 'Inflation, output growth, and nominal and real uncertainty: Empirical evidence for the G7.' Journal of International Money and Finance, 26, 229-250.

Gaggle P. and Steindl, S. (2007). 'Business Cycles and Growth: A Survey', WIFO Working Papers, No. 308

Gourieroux C. and Monfort, A. (1996). Time Series and Dynamic Models. Cambridge University Press: Cambridge.

Granger, C. (1988). 'Some recent developments in a concept of causality.' Journal of Econometrics, 39, 199-212.

Grier, K.B., Henry, O.T., Olekalns, N. and Shields, K. (2004). 'The asymmetric effect of uncertainty on inflation and output growth.' Journal of Applied Econometrics, 19, 551-565.

Grier, K.B. and Perry, M.J. (2000). 'The effect of real and nominal uncertainty of inflation and output growth: Some GARCH-M evidence.' Journal of Applied Econometrics, 15, 45-58.

Hochberg Y. (1988). 'A sharper Bonferroni procedure for multiple test of significance', Biometrika, 75, 4, 800-2.

Jones, L.E., Manuellim, R.E., Siu, H.and Stacchetti, E. (2005). 'Fluctuations in convex models of endogenous growth, I: Growth effects.' Review of Economic Dynamics 8, 780-804.

Kose M.A., Prasad, E.S. and Terrones, M.E. (2005). 'Growth and Volatility in an Era of Globalization', IMF Staff Papers, 52, Special Issue, 31-63.

Lamoureux C. and Lastrapes B. (1990). 'Persistence-in-Variance, Structural Change, and the GARCH Model'. Journal of Business and Economic Statistics, 8, 225-234. 
Levine, R. and Renelt, D. (1992). 'A sensitivity analysis of cross-country growth regressions.' The American Economic Review, 82, 4, 942-963.

Manacorda, M. (2002). 'Wage indexation and the evolution of returns to education in Italy,1978-1992', in Richard B. Freeman (ed.), Inequality Around the World, Palgrave.

Martin, P. and Rogers, C.A. (2000). 'Long-term growth and short-term economic instability.' European Economic Review, 44, 359-381.

OECD (1984). Economic Surveys, France, 1983/1984, Paris.

Peel, D.A. and Speight, A.E.H. (1998). 'Modelling business cycle nonlinearity in conditional mean and conditional variance: some international and sectoral evidence.' Economica, 65, 211-229.

Pelloni, A. (1997). 'Nominal shocks, endogenous growth and the business cycle.' Economic Journal, 107, 467-74.

Ramey, G. and Ramey, V.A. (1995). 'Cross-country evidence on the link between volatility and growth.' American Economic Review, 85, 1138-1152.

Rom, D.M. (1990). 'A sequential rejective test procedure based on a modified Bonferroni inequality', Biometrika, 77, 3, 663-5.

Romer, P.M. (1986). 'Increasing returns and long-run growth.' Journal of Political Economy, 94, 1002-1037.

Stock, J.H. and Watson, M.W. (2003). 'Forecasting Output and Inflation: the Role of Asset Prices.' Journal of Economic Literature, 41, 788-829.

Temple, J. (2000). 'Inflation and growth: stories short and tall.' Journal of Economic Surveys, 14, 395-426.

Wang, P. and Yip C. (1992). 'Alternative approaches to money and growth.' Journal of Money, Credit and Banking, 24, 4, 552-562. 
Table 1: Summary results of the estimated Bivariate GARCH-M model for the money and output growth in the G7

\begin{tabular}{|c|c|c|c|c|c|c|c|c|}
\hline Sample & & $\begin{array}{c}1962: 03 \text { - } \\
\text { 2006:10 }\end{array}$ & $\begin{array}{c}\text { 1961:03 - } \\
\text { 2006:10 }\end{array}$ & $\begin{array}{c}\text { 1961:03 - } \\
\text { 2003:7 }\end{array}$ & $\begin{array}{c}\text { 1965:03 - } \\
\text { 2006: } 10\end{array}$ & $\begin{array}{c}\text { 1961:02 - } \\
\text { 2006:10 }\end{array}$ & $\begin{array}{c}1970: 08 \text { - } \\
\text { 2006:12 }\end{array}$ & $\begin{array}{c}1961: 02- \\
\text { 2006: } 12\end{array}$ \\
\hline Hypotheses: & \begin{tabular}{|c|} 
Parameter \\
Restrictions
\end{tabular} & Canada & France & Germany & Italy & Japan & $\mathbf{U K}$ & $\mathbf{U S}$ \\
\hline \multirow[t]{2}{*}{ (i) Money volatility in (23) } & $\alpha_{1}=0$ & $\begin{array}{l}0.0916 \\
(3.91)^{*}\end{array}$ & $\begin{array}{c}0.0683 \\
(1.73) \\
\end{array}$ & $\begin{array}{l}0.2120 \\
(3.83)^{*}\end{array}$ & $\begin{array}{l}0.4853 \\
(4.07)^{*}\end{array}$ & $\begin{array}{l}0.1346 \\
(2.46)^{*}\end{array}$ & $\begin{array}{l}0.3157 \\
(3.71)^{*}\end{array}$ & $\begin{array}{l}0.2010 \\
(3.11)^{*}\end{array}$ \\
\hline & $\alpha_{2}=0$ & $\begin{array}{c}0.8624 \\
(19.58)^{*}\end{array}$ & $\begin{array}{c}0.9211 \\
(18.73)^{*}\end{array}$ & $\begin{array}{c}0.0488 \\
(0.40)\end{array}$ & $\begin{array}{c}0.0735 \\
(0.64) \\
\end{array}$ & $\begin{array}{c}0.8270 \\
(11.33)^{*}\end{array}$ & $\begin{array}{l}0.1042 \\
(2.52) *\end{array}$ & $\begin{array}{l}0.7145 \\
(8.79)^{*}\end{array}$ \\
\hline \multirow[t]{2}{*}{ (ii) Output volatility in (25) } & $\alpha_{4}=0$ & $\begin{array}{l}0.1029 \\
(2.00)^{*}\end{array}$ & $\begin{array}{l}0.1779 \\
(2.90)^{*}\end{array}$ & $\begin{array}{l}0.3722 \\
(4.13)^{*}\end{array}$ & $\begin{array}{l}0.0510 \\
(3.66)^{*}\end{array}$ & $\begin{array}{c}0.1064 \\
(0.84)\end{array}$ & $\begin{array}{c}0.0530 \\
(1.89)\end{array}$ & $\begin{array}{l}0.2819 \\
(3.22)^{*}\end{array}$ \\
\hline & $\alpha_{5}=0$ & $\begin{array}{l}0.5773 \\
(4.78)^{*} \\
\end{array}$ & $\begin{array}{c}0.1801 \\
(0.68) \\
\end{array}$ & $\begin{array}{l}0.1465 \\
(2.29)^{*} \\
\end{array}$ & $\begin{array}{c}0.9456 \\
(75.02)^{*} \\
\end{array}$ & $\begin{array}{c}0.0354 \\
(0.05) \\
\end{array}$ & $\begin{array}{c}0.9443 \\
(36.71)^{*} \\
\end{array}$ & $\begin{array}{c}0.1535 \\
(0.99) \\
\end{array}$ \\
\hline (iii) Money volatility in (22) & $\beta_{3}=0$ & $\begin{array}{l}-0.1614 \\
(-2.34)^{*}\end{array}$ & $\begin{array}{c}-0.0092 \\
(-0.15)\end{array}$ & $\begin{array}{c}-0.2036 \\
(-0.98)\end{array}$ & $\begin{array}{l}-0.1853 \\
(-2.40)^{*}\end{array}$ & $\begin{array}{c}-0.1121 \\
(-1.91)\end{array}$ & $\begin{array}{c}-0.1744 \\
(-0.61) \\
\end{array}$ & $\begin{array}{c}-0.2229 \\
(-1.16)\end{array}$ \\
\hline (iv) Output volatility in (22) & $\beta_{4}=0$ & $\begin{array}{c}0.0640 \\
(0.29) \\
\end{array}$ & $\begin{array}{c}-0.1181 \\
(-1.38) \\
\end{array}$ & $\begin{array}{c}-0.0243 \\
(-0.66) \\
\end{array}$ & $\begin{array}{l}0.0923 \\
(3.73)^{*} \\
\end{array}$ & $\begin{array}{c}0.1846 \\
(0.46) \\
\end{array}$ & $\begin{array}{l}0.0605 \\
(2.46)^{*} \\
\end{array}$ & $\begin{array}{c}0.0366 \\
(0.55) \\
\end{array}$ \\
\hline (v) Money volatility in (24) & $\beta_{8}=0$ & $\begin{array}{c}-0.1331 \\
(-2.02)^{*}\end{array}$ & $\begin{array}{c}0.0020 \\
(0.02)\end{array}$ & $\begin{array}{l}-0.4093 \\
(-2.33)^{*}\end{array}$ & $\begin{array}{c}0.0046 \\
(0.07)\end{array}$ & $\begin{array}{c}-0.0161 \\
(-0.37)\end{array}$ & $\begin{array}{c}0.4778 \\
(1.22)\end{array}$ & $\begin{array}{c}-0.343 \\
(-1.56)^{* *}\end{array}$ \\
\hline (vi) Output volatility in (24) & $\beta_{9}=0$ & $\begin{array}{l}1.0224 \\
(2.63)^{*}\end{array}$ & $\begin{array}{l}0.2133 \\
(2.20)^{*}\end{array}$ & $\begin{array}{c}0.0417 \\
(0.81) \\
\end{array}$ & $\begin{array}{c}0.0344 \\
(1.06) \\
\end{array}$ & $\begin{array}{c}0.3180 \\
(0.49) \\
\end{array}$ & $\begin{array}{c}-0.0234 \\
(-0.30) \\
\end{array}$ & $\begin{array}{l}0.4481 \\
(2.78)^{*}\end{array}$ \\
\hline (vii) Money growth in (24) & $\beta_{7 i}=0$ & $\begin{array}{c}24.9249 \\
{[0.000]}\end{array}$ & $\begin{array}{l}11.4984 \\
{[0.003]}\end{array}$ & $\begin{array}{c}0.3968 \\
{[0.000]}\end{array}$ & $\begin{array}{c}1.8428 \\
{[0.175]}\end{array}$ & $\begin{array}{c}43.266 \\
{[0.000]}\end{array}$ & $\begin{array}{c}0.2077 \\
{[0.649]}\end{array}$ & $\begin{array}{c}3.6746 \\
{[0.055]}\end{array}$ \\
\hline Sum of money coeffs in (24) & $\sum \beta_{7 i}$ & 0.0952 & 0.2065 & 0.4908 & 0.2695 & 0.1825 & -0.1083 & 0.1148 \\
\hline
\end{tabular}

Note: In each case we report the estimated parameters of the bivariate GARCH-M in equations (22)-(26) and the corresponding t-statistic in the parenthesis with the round brackets. The square brackets in the last row for hypothesis (vii) refer to chi-squared statistic with associated p-values. $(*)$ and $(* *)$ denote rejection of the null hypothesis at the $5 \%$ and $10 \%$ significance levels, respectively. 


\section{Appendix A: Theoretical Derivations}

Derivation of equations (14) and (16): substituting the expression for the interest rate in terms of income and capital from (8) in (11) and recall the that $C_{t}+K_{t+1}=Y_{t}$ we are able to rewrite (11) as

$$
\frac{\gamma_{t} K_{t+1}}{C_{t}}=\sigma \beta \psi \mu_{\gamma}+\sigma \beta \psi E_{t}\left(\frac{\gamma_{t+1} K_{t+2}}{C_{t+1}}\right)
$$

this defines a stochastic difference equation. Considering the transversality condition $\lim _{\tau_{\tau \rightarrow \infty}} \beta^{\tau} E_{t}\left(\gamma_{t+\tau} K_{t+\tau+1} / C_{t+\tau}\right)=0$ its solution is given by:

$$
K_{t+1}=\frac{a \mu_{\gamma}}{(1-a) \gamma_{t}} C_{t}
$$

where $a \equiv \sigma \beta \psi$. Given $C_{t}+K_{t+1}=Y_{t}$ (2A) implies (14) and (16) in the text.

Given $H_{t}=H_{t-1} \phi_{t}$ and $M_{t}=H_{t}(12)$ becomes

$$
\frac{\gamma_{t} M_{t}}{P_{t} C_{t}}=\theta+\beta E_{t}\left(\frac{\gamma_{t+1} M_{t+1}}{P_{t+1} C_{t+1}}\right)
$$

solving (3A) by using the other transversality condition

$$
\lim _{{ }_{\tau \rightarrow \infty}} \beta^{\tau} E_{t}\left(\left(\gamma_{t+\tau} M_{t+\tau-1} \phi_{t+\tau}\right) / P_{t+\tau} C_{t+\tau}\right)=0
$$

we get: $\frac{\gamma_{t} M_{t}}{P_{t} C_{t}}=\frac{\theta}{1-\beta}$ and substituting in for consumption its expression in terms of income given by (14) we have (15) in the text.

Derivation of equation (17): this is obtained by substituting in (13) for consumption its expression in terms of income given by (14) and then using (7). 
Derivation of equation (17'): by substituting in (13') for consumption its expression in terms of income given by (14) and then using (7) we obtain: $E_{t-1} N_{t}=\frac{\alpha^{2} \mu_{\gamma} \sigma}{\lambda(1-a)}$. Substituting in (15) the expression for income in terms of labour and the real wage given by (7) we get:

$$
N_{t}=\frac{\alpha \sigma(1-\beta)\left((1-a) \gamma_{t}+\mu_{\gamma}\right)}{(1-a) \theta W_{t}} M_{t}
$$

Or, taking expectations: $E_{t-1} N_{t}=\frac{\alpha \sigma(1-\beta) \mu_{\gamma}}{(1-a) \theta W_{t}} E_{t-1} M_{t}$. Equating the two expressions for $E_{t-1} N_{t}$ we get the optimal wage: $W_{t}=\frac{\lambda(1-\beta) E_{t-1}\left(M_{t}\right)}{\alpha \theta}$. Finally substituting this expression for the optimal wage in (4A) we get (17').

Derivation of equation (17'): eliminating the real wage from (7) and (13') we get: $\alpha \sigma N_{t}^{\alpha-1}=\frac{\lambda}{E_{t-1} \gamma_{t} K_{t} / C_{t}}$. Using (14) to express consumption in terms of income and then using (6) to eliminate $Y_{t}$ we get: $\alpha \sigma N_{t}^{\alpha-1}=\frac{\lambda}{E_{t-1} \alpha\left[(1-a) \gamma_{t}+a \mu_{\gamma}\right] /(1-a) N_{t}^{\alpha}}$ which, since at time t-1 $N_{t}$ is known, can be rearranged to give (17'') in the text. 


\section{Appendix B: Data Appendix}

Table B1: G7 Data Definitions and Descriptions

\begin{tabular}{|l|l|l|}
\hline Country & Money & Output \\
\hline Canada & $\begin{array}{l}\text { M1 money supply, Datastream } \\
\text { CNM1...B (1961m1-2006m10) }\end{array}$ & $\begin{array}{l}\text { OECD industrial production index } \\
\text { (excluding construction) }\end{array}$ \\
\hline France & $\begin{array}{l}\text { OECD M1 money supply (1960-1977 } \\
\text { from OECD Historical Statistics), SA } \\
\text { NSA M1 Money Supply: - French } \\
\text { Contribution to the Euro Area, } \\
\text { Datastream FRM1....A (1980-2006m10) }\end{array}$ & $\begin{array}{l}\text { OECD industrial production index } \\
\text { (excluding construction) }\end{array}$ \\
\hline Germany & $\begin{array}{l}\text { M1 MONEY SUPPLY- (Contribution to } \\
\text { Euro Basis from 1995m1), SA }, \\
\text { Datastream BDM1...B (1960-2003m7) }\end{array}$ & $\begin{array}{l}\text { OECD index of industrial production } \\
\text { (excluding construction) }\end{array}$ \\
\hline Italy & $\begin{array}{l}\text { OECD M1 money supply (1964-1980 } \\
\text { from OECD Historical Statistics), SA. } \\
\text { NSA M1 Money Supply: - Italian } \\
\text { Contribution to the Euro Area, } \\
\text { Datastream ITM1...A (1980-2006m10) }\end{array}$ & $\begin{array}{l}\text { OECD industrial production index } \\
\text { (excluding construction) }\end{array}$ \\
\hline Japan & $\begin{array}{l}\text { M1 money supply, Datastream } \\
\text { JPM1FMONB (1960-2006m10) }\end{array}$ & $\begin{array}{l}\text { OECD industrial production index } \\
\text { (excluding construction) }\end{array}$ \\
\hline US & $\begin{array}{l}\text { FRED M1 money stock (M1SL) (1960- } \\
\text { 2006m12) }\end{array}$ & $\begin{array}{l}\text { FRED industrial production index } \\
\text { (excluding construction, INDPRO) }\end{array}$ \\
\hline UK & $\begin{array}{l}\text { Money Supply M0: Notes \& Coins in } \\
\text { circulation outside Bank of England, } \\
\text { Datastream UKM0....B (1969m6- } \\
\text { 2006m12) }\end{array}$ & $\begin{array}{l}\text { OECD industrial production index } \\
\text { (excluding construction) }\end{array}$ \\
\hline
\end{tabular}

Data Sources:

OECD - Organisation for Economic Co-operation and Development;

FRED - Federal Reserve Economic Data.

Table B2: G7 Outliers Removed

\begin{tabular}{|l|l|l|}
\hline Country & Money & Output \\
\hline Canada & $1981 \mathrm{~m} 12$ & none \\
\hline Euro Area & $\begin{array}{l}1990 \mathrm{~m} 6 ; 1999 \mathrm{~m} 1 ; 2000 \mathrm{~m} 1 ; 2001 \mathrm{~m} 1 ; \\
2005 \mathrm{~m} 6\end{array}$ & none \\
\hline France & $1968 \mathrm{~m} 5 ; 1977 \mathrm{~m} 12 ; 1995 \mathrm{~m} 12$ & $1963 \mathrm{~m} 3,4 ; 1968 \mathrm{~m} 5-7$ \\
\hline Germany & $\begin{array}{l}1964 \mathrm{~m} 1 ; 1965 \mathrm{~m} 1 ; 1966 \mathrm{~m} 1 ; 1967 \mathrm{~m} 1,11 ; \\
1968 \mathrm{~m} 1,11 ; 1969 \mathrm{~m} 1,1973 \mathrm{~m} 5 ; 1990 \mathrm{~m} 6, \\
12\end{array}$ & $1968 \mathrm{~m} 1,1984 \mathrm{~m} 6,7$ \\
\hline Italy & $1970 \mathrm{~m} 1 ; 1972 \mathrm{~m} 12 ; 1973 \mathrm{~m} 1$ & $1974 \mathrm{~m} 1$ \\
\hline Japan & $1990 \mathrm{~m} 5 ; 2002 \mathrm{~m} 3$ & none \\
\hline US & $2001 \mathrm{~m} 9-10$ & $1974 \mathrm{~m} 11-12$ \\
\hline UK: M0 & $1971 \mathrm{~m} 2,4 ; 1999 \mathrm{~m} 12,2000 \mathrm{~m} 2$ & $\begin{array}{l}1972 \mathrm{~m} 2-3 ; 1974 \mathrm{~m} 1 ; 1978 \mathrm{~m} 4 ; 1979 \mathrm{~m} 1-2, \\
2002 \mathrm{~m} 6\end{array}$ \\
\hline UK: MC & $1971 \mathrm{~m} 2,4 ; 1977 \mathrm{~m} 6 ; 1999 \mathrm{~m} 12,2000 \mathrm{~m} 2$ & $\begin{array}{l}1972 \mathrm{~m} 2-3 ; 1974 \mathrm{~m} 1 ; 1978 \mathrm{~m} 4 ; 1979 \mathrm{~m} 1-2, \\
2002 \mathrm{~m} 6\end{array}$ \\
\hline
\end{tabular}

Note: The above outlier observations are removed by Stock and Watson's (2003) inter-quartile range method. 